\title{
LATE-ONSET LIPIDSTORAGEMYOPATHYMIMICKINGANINFLAMMATORY MYOPATHY: A CASE REPORT
}

Joâo Paulo Peres Lima ${ }^{1, \star}$, Isadora Medina ${ }^{1}$, Isaac Felipe Leite Braz${ }^{1}$, Izaura Tereza Silva Guedes ${ }^{1}$, Leonardo Afonso Costa ${ }^{1}$, Lucas de Castro Barroti ${ }^{1}$, Míriam Fang Castro ${ }^{1}$, Rodrigo Lorenzetti Serrano ${ }^{1}$, Marcela Miguens Castelar Pinheiro ${ }^{1}$, Renan Rodrigues Neves Ribeiro do Nascimento ${ }^{1}$, Edgar Torres dos Reis Neto ${ }^{1}$

1.Universidade Federal de São Paulo, São Paulo (SP), Brazil.

*Corresponding author: joaopaulopereslima@gmail.com

\section{BACKGROUND}

Myopathies are characterized by muscle weakness with or without myalgia. The underlying etiologies include autoimmune diseases, metabolic disorders, drugs, endocrinopathies and infections. The clinical phenotypes of myopathies can be extremely variable and the severity of these disorders ranges from mild exercise intolerance to life-threatening conditions. Variations in clinical manifestations, laboratory tests and muscle biopsy can be helpful in diagnosis.

\section{CASE REPORT}

A 28-year-old white woman presented to the emergency department with proximal muscular weakness of the upper and lower limbs during the previous 8 months. In addition, she also reported noninflammatory symmetrical polyarthralgia, pruritic erythematous plaques involving trunk, extremities and scalp, dysphagia and unintentional weight loss of $30 \mathrm{~kg}$. Prior to the onset of symptoms, she reported exercise intolerance and two episodes of exercise-induced muscle weakness, associated with myalgia and dark urine. Neurological examination showed symmetrical proximal weakness of the upper and lower limbs. The initial laboratory results were significant for creatine kinase levels of $1520 \mathrm{U} / \mathrm{L}$ (26-192 U/L), with normal levels of erythrocyte sedimentation rate and C-reactive protein. Hepatic function tests revealed an alanine aminotransferase of $131 \mathrm{U} / \mathrm{L}(\leq 33 \mathrm{U} / \mathrm{L})$ and an aspartate aminotransferase of $168 \mathrm{U} / \mathrm{L}(\leq 32 \mathrm{U} / \mathrm{L}$ ). Urinary tests indicated a pattern of myoglobinuria. Viral serology and autoimmune panel results were negative. Magnetic resonance imaging showed mild symmetrical edema of the adductor longus, semimembranosus and biceps femoris. Results of electromyography and nerve conduction studies were suggestive of myopathy involving mainly the proximal muscles. Patient was given $40 \mathrm{mg}$ prednisone daily, with improvement in muscle and cutaneous symptoms. Later, azathioprine was associated as a glucocorticoid-sparing therapy. After reduction of the glucocorticoid, the patient developed worsening of symptoms and increased creatine kinase levels. At this point, after a dermatological evaluation, the skin lesions were diagnosed as psoriasis. A muscle biopsy was performed and showed multiple vacuoles with positive staining for oil red $\mathrm{O}$, suggesting lipid storage myopathy. Given the new diagnosis, immunosuppressive therapy was discontinued and genetic evaluation was requested.

\section{CONCLUSION}

Lipid storage myopathy is characterized by lipid accumulation in muscle fibers due to lipid dysmetabolism. Is a rare heterogeneous genetic condition that is difficult to identify because of the low incidence and has no specific treatment.

\section{KEYWORDS}

Lipid storage myopathy, Myopathy, Muscle weakness. 